\title{
Unicuspid Aortic Valve: A Rare Congenital Anomaly
}

\author{
Jianhong Pan \\ Department of Internal Medicine, Tianjin NanKai Hospital, Tianjin, China
}

\section{Keywords}

Unicuspid aortic valve · Echocardiography · Aortic stenosis

\begin{abstract}
Unicuspid aortic valve (UAV) is a rare congenital aortic valve anomaly. It has 2 subtypes and often is associated with aortic valve dysfunction and corresponding clinical presentations. Echocardiography is the first choice of diagnostic method for UAV. Three-dimensional echocardiography has played an increasingly important role in diagnosis, intraprocedural guidance, and post-procedural assessment in recent years. There remain challenges in distinguishing UAV from bicuspid aortic valve or tricuspid aortic valve. Misdiagnosis is most resulted from raphes or leaflet calcifications. Multi-modality imaging has obvious advantages over single-modality imaging and is crucial for UAV diagnosis. Accurate identification of aortic valve morphology is important to choose the best treatment. Aortic balloon valvoplasty, surgical valvotomy, commissurotomy, Ross procedure, surgical valve repair, and surgical replacement are most common treatment modalities of UAV. In this review, we aim to discuss UAV including epidemiology, definition, classification, diagnostic importance and necessity, valvular function, clinical presentation, associated disorders, noninvasive diagnostic modalities, and therapeutic approaches.

(c) 2021 S. Karger AG, Base
\end{abstract}

karger@karger.com

(C) 2021 S. Karger AG, Basel

www.karger.com/crd

Karger!

\section{Introduction}

Unicuspid aortic valve (UAV) is a rare congenital malformation that was first reported by Edwards in 1958 [1]. UAV has been categorized into 2 subtypes: acommissural UAV and unicommissural UAV. UAV is associated with severe aortic stenosis (AS) and/or aortic regurgitation (AR). In the former type, symptoms often present early in infancy due to severe stenosis, while in the latter type, symptoms present later in adulthood with a more benign course. Some echocardiographic features are valuable hints to facilitate diagnosis. It is easy to mistake UAV as bicuspid aortic valve (BAV) or tricuspid aortic valve (TAV) in sometimes. In this review, we focus specifically on the epidemiology, definition, classification, diagnostic importance and necessity, valvular function, clinical presentation, associated disorders, noninvasive diagnostic modalities, and therapeutic approaches of UAV. Comprehensive description of UAV like this has not been reported in the literature previously.

\section{Epidemiology}

$\mathrm{UAV}$ is a rare congenital cardiac anomaly with an incidence of about $0.02 \%$ in adults undergoing echocardiography [2] and approximately $4 \sim 5 \%$ in the patients 
Table 1. The difference between acommissural UAV and unicommissural UAV

\begin{tabular}{lll}
\hline & Acommissural UAV & Unicommissural UAV \\
\hline Commissures, $n$ & 0 & 1 \\
Lateral attachment at or above the level of the coronary ostium, $n$ & 0 & 1 \\
Orifice shape & Pinhole shaped & Teardrop shaped \\
Orifice position & Sentral orifice & Eccentric orifice \\
Effective orifice area & Mmall & Larger than acommissural UAV \\
Patients' age & Mainly in infants and children & In infants, children, and adult \\
Appearance time of the symptoms & in life, even at birth & adulthood \\
& & \\
\hline
\end{tabular}

who undergo surgery for AS [3]. This abnormality is predominantly found in males (male-to-female ratio, 4:1) [4]. UAV is a frequent reason for aortic valve operation in adolescents under the age of 25 years [5]. Congenital aortic valve malformation usually present as a bicuspid, quadricuspid, pentacuspid, or UAV [6]. BAV is well known as the most common one among them. Compared with BAV which has an estimated prevalence of 0.9$1.36 \%$ in the general population [7], UAV is rare. Genetic analysis has established the heritable nature of BAV. In spite of the significant male predominance similar to $\mathrm{BAV}$, UAV has not been proved to be heritable and no clearly genetic abnormalities have been identified up to now [8-10].

UAV was once mainly discovered by the pathological examination of surgically excised valves or as an incidental finding at autopsy. The preoperative diagnosis of UAV was rare because of the limitations inherent to early echocardiographic techniques and the lack of a clear consensus on the definition of UAV [8]. Consequently, the true prevalence of UAV may be underestimated.

\section{Definition and Classification}

UAV, as the name suggests, only has a single aortic valve leaflet, with or without the visualization of raphes. Two subtypes have been described in the literature: acommissural UAV and unicommissural UAV [11] (Table 1; Fig. 1). Both have a dome shape. The acommissural form has a pinhole-shaped central orifice, without commissure, and without lateral attachment to the aorta at or above the level of the coronary ostium, while the unicommisural form has an eccentric "teardrop" orifice, with one commissure and with a lateral attachment to the aorta at or above the level of the coronary ostium $[3,12]$. The latter type owns relatively larger effective orifice area than that of its acommissural counterpart during systole $[1,12,13]$. Compared to infants, UAVs are relatively uncommon in adults [14]. UAVs can be acommissural type among infants and children, while in adults, UAVs are mainly unicommissural type [15-17]. In unicommissural UAV, the leaflet itself was not divided except by one complete commissure [18]. The single cusp wraps around the aortic orifice and back to its original point.

The zone of apposition is different from the commissure (Fig. 2). The zone of apposition between the leaflets is no more than the line of union between two adjacent structures, as in the lips or eyelids. The commissure is defined as the space between the two lateral attachments of two adjacent leaflets to the aortic wall normally not adhering to each other $[1,19,20]$. Although the single commissure in unicommissural UAV can be located at different position between the three fused cusps, a posteriorly positioned commissure between the anatomic noncoronary and left coronary cusp may be most common (Fig. 1a) $[2,11,15,16]$. The commissure in UAV is less located at the junction of the left and right coronary cusps (Fig. 3), and least at the junction of right coronary and noncoronary cusps $[15,16]$.

The raphe is different from the commissure as well. A raphe refers to the fused area of two underdeveloped cusps (Fig. 4). Raphe is a ridge containing aortic medial elastic fibers tissue that extends from the aortic wall, along the aortic face of the conjoined leaflet, but it usually does not extend very far [1]. The raphes usually do not reach the free edges of the cusp. It may be looked on as an abortive commissure between two adjacent cusps $[1,20]$. Unicommissural UAV may have at most two such raphes [18]. The aortic valve retains the normal anatomic division into left, right, and noncoronary cusps when UAV has two raphes, but there was no separation of the cusps $[16,19]$. Different attachment level is also an important 


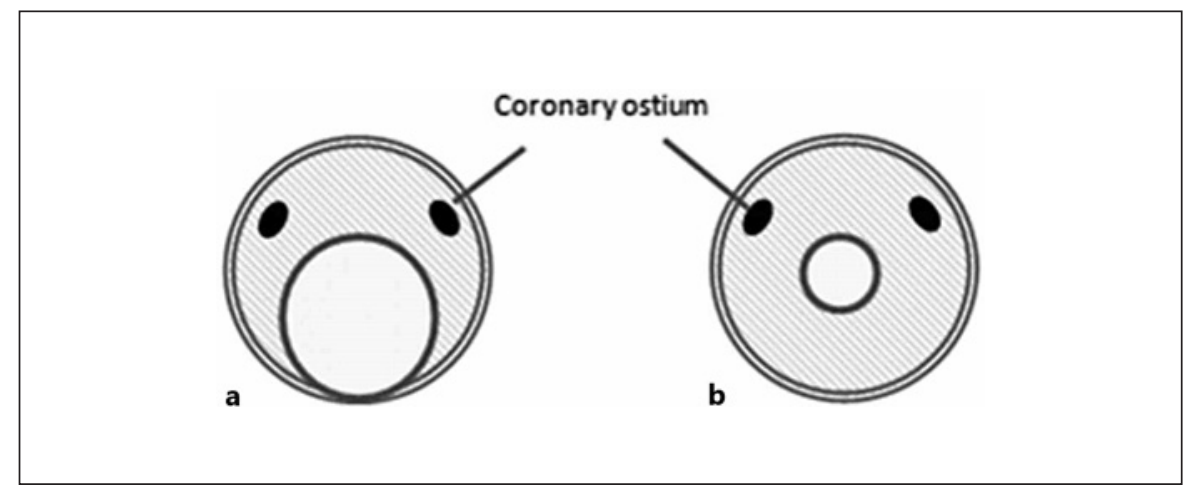

Fig. 1. Schematic representation of the UAV. a Unicommissural UAV. During systole, note a single commissure located posteriorly. b Acommissural UAV. During systole, note a pinhole-shaped central orifice, without commissure.
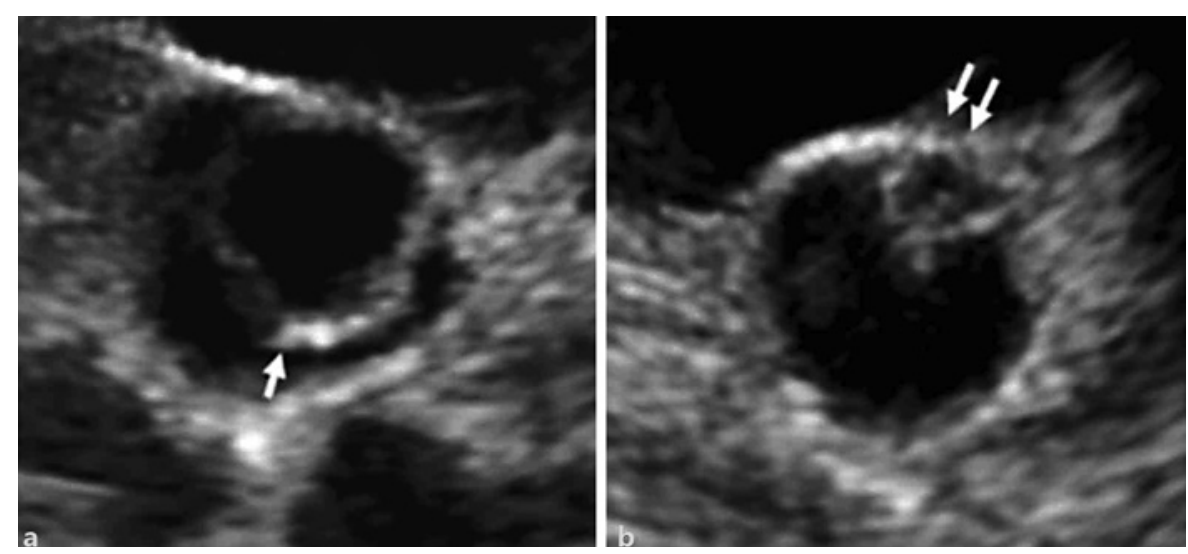

Fig. 3. 2D TTE of a congenital UAV at the parasternal short-axis view. a During systole, note an eccentric valvular orifice and a rounded leaflet free edge (arrow). b In late diastole, note a single commissural attachment zone located at the junction of the left and right coronary cusps (double arrow).

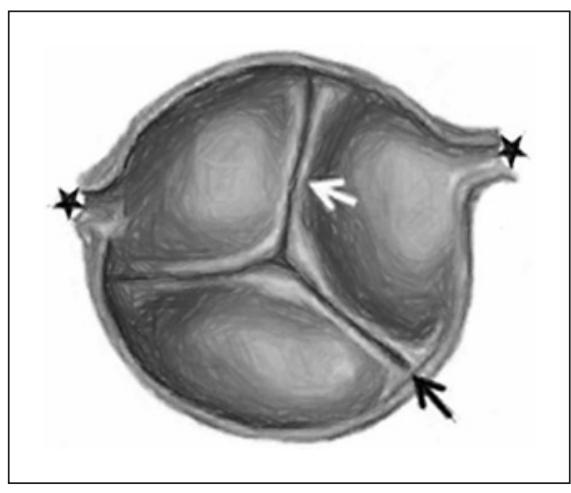

Fig. 2. Schematics of the zone of apposition (white arrow) and the commissure (black arrow) of aortic valve. Black asterisk: coronary ostium.

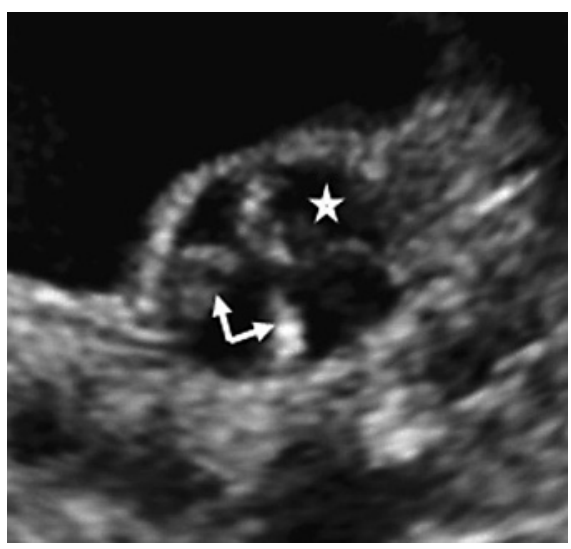

Fig. 4. TTE short-axis view of a unicommissural UAV showed two raphes (arrow) and an eccentric orifice (asterisk). distinguishment between commissure and raphe: the commissure lies at or higher than the level of coronary ostia, but the raphe always lies lower than the ostia.

\section{Importance and Necessity of UAV Diagnosis}

As therapeutic options for aortic valve disease increasing due to the further development of surgical valve repair and the growth in the popularity of transcatheter aortic valve implantation (TAVI) [21,22], the exact preoperative diagnosis of aortic valve morphology is required for clinician to choose the best treatment, such as intervention, reconstruction, or replacement.

Unicuspid Aortic Valve
Aortic valve repair may be an alternative to valve replacement in selected UAV patients with severe valve dysfunction. This Approach can potentially avoid the problems associated with valvular replacement (e.g., avoid anticoagulation and valve related complications), especially in juvenile patients or young adults [21, 23]. UAV repair requires very specific and individualized repair approaches. Hence, accurate description of valve morphology and precise evaluation of aortic valve are useful for appropriate surgical repair strategy [24-26].

In recent years, TAVI has been widely used for patients at high risk of surgery or with surgical contraindications who have severe AS $[27,28]$. BAV was once regarded as contraindication for TAVI [28]. However, indications for 
TAVI have been increasing and increasing data have demonstrated the feasibility, safety, and efficacy of TAVI in selected BAV patients [29]. UAV patients have not been considered as appropriate candidates for TAVI and there have been no reports concerning TAVI for UAV patients so far. It would be valuable to identify the valve morphology for AS patients in the present era of TAVI $[22,27]$.

\section{Valvular Function and Clinical Presentation}

The predominant valvular lesion of UAV is isolated AS, followed by AS concomitant with AR. Isolated AR is uncommon $[8,12,30]$. UAV has marked bimodal age presentation, either severe left ventricular outflow obstruction in fetal life or early infancy, or degenerative AS or mixed aortic valvar disease in the third to fifth decades of life [19].

A normal aortic valve consists of three cusps which develop from three tubercles of the aortic trunk at the embryonic stage [31]. The fusion of all cusps or failure to separate results in a UAV $[3,18]$. Thus, its total length of leaflet free edge is much shorter than that of TAV [15]. The raphes might interfere with the free motion of the leaflet as well [1]. These make a narrow opening of UAV. UAV has more early, more accelerated, more severe valvular calcification as well as a smaller orifice than BAV or TAV, which would lead to more early, more accelerated and more severe AS in UAV than in BAV or TAV [3234]. Likewise, UAV patients present associated clinical symptoms of AS at earlier age and progress faster $[4,8$, 35 . Also, the irregularly deposited calcific spurs may prevent the cusp from closing the orifice, thus AR may occur [1]. Adult UAV patients often have both AS and AR, while pediatric patients commonly present with AS alone $[15,36]$.

In adult, the most common symptoms of UAV include dyspnea, angina, dizziness, and syncope [36]. Pediatric patients always present with left heart failure and failure to thrive. Pneumonia could be manifested in UAV patients within the first 2 months of life [14]. The prominent abnormal finding in physical examination is the presence of a cardiac murmur at the aortic area. Auscultation revealed a systolic, diastolic, or to-and-fro cardiac murmur depending on the predominant valvular lesion $[18,37]$. The murmur varied in loudness and occasionally may be faint [22]. The murmur could conduct along the left sternal border or radiate to the carotid and may be accompanied by thrill in a few patients $[14,27]$.
The acommissural variant is generally accompanied by severe AS and the associated symptoms of left heart failure that occurs early in life, even at birth $[8,14,38]$. The unicommissural form appears to have a less-aggressive course. It usually develops symptoms until adulthood since the formation of a commissure brings a relatively larger valvular orifice area compared to acommissural type $[4,5,8,12,35,39,40]$. Moreover, the valvular lesion would progress further with the aging, the accelerated leaflet calcification and fibrosis resulted from the aortic valve malformation $[13,38,41]$.

\section{Associated Disorders}

UAV may also be accompanied by other abnormalities, such as aortopathy, patent ductus arteriosus, ventricular septal defect, and anomalous coronary artery [12, 40]. Concurrent aortopathy comprises aortic dissection, coarctation of the aorta, dilatation or aneurysm of the aortic annulus, aortic root or ascending aorta [38, 42]. Nearly half (48\%) adult UAV patients coexist with ascending aortic dilatation which may be caused by a synergistic effect of hemodynamic stress and a congenitally inherited weakness of the aortic media. Whereas ascending aortic dilatation is less common in pediatric patients for the relatively short-term effect of hemodynamic stress $[2,40,43]$. Reconstruction of the aortic sinuses or replacement of the ascending aorta is recommended when the diameter of the aortic sinuses or ascending aorta is greater than $55 \mathrm{~mm}$ [44]. The histopathological findings of the aortic dilatation in UAV include medial degeneration, increased matrix metalloproteinase (MMP) activity, and decreased fibrillin-1 in the aortic wall $[19,45,46]$, which are similar to the aortic dilatation in BAV and Marfan syndrome. Aortic dilatation in UAV may have bimodal distribution: older UAV patients presenting the less-aggressive form without pathological aortic dilatation, and aggressive form shown in younger UAV patients with pathological aortic dilatation $[11,36,47]$. One report showed that $46 \%$ UAV patients had ascending aorta aneurysm, and the patients who had ascending aorta aneurysm were younger compared with those who did not [11].

Moreover, UAV patients have higher risk of aortic dissection. UAV and BAV patients have, respectively, 18 and 9 times the risk of aortic dissection in TAV patients [36, $48,49]$. Also, aortic dissection occurs earlier in UAV patients than in BAV and TAV patients [49]. In UAV, the accompanying coronary artery anomalies may include a 
single coronary artery and anomalous origin of coronary artery $[2,50]$. The development of aortic leaflets and coronary arteries may be affected by the same derangements. That can explain the frequent concurrence of abnormalities between the aortic valve and coronary arteries $[8,36]$. Infective endocarditis is another valvular complication in UAV.

In some patients, UAV may be part of the heart-hand syndrome in which heart defects occurs together with limb abnormalities [37] or part of hypoplastic left ventricle syndrome which commonly has congestive cardiac failure during infancy [14]. In addition, heavy calcification could extend into the interventricular septum which possibly results in conduction system damage during debridement. Permanent pacemaker implantation would be recommended when persistent complete heart block is encountered $[4,8,36]$.

\section{Noninvasive Diagnostic Modalities}

\section{Echocardiography}

Echocardiography remains the gold standard for noninvasive diagnosis and evaluation of valvular abnormalities, including UAV [51]. But previously preoperative diagnosis of UAV was often difficult. Along with the significant improvements and recent advances in technology and imaging, as well as the echocardiographic features of UAV becoming widely recognized, accurate preoperative diagnosis of UAV can be acquired by echocardiography, which has been confirmed by surgical findings $[4,11$, $12,15,39,52]$.

The unicommissural type is most frequently encountered. Some studies have described the echocardiographic characteristics of this type and take them as major echocardiographic diagnostic criteria which have been confirmed by surgery: (a) single commissural attachment zone, (b) rounded leaflet free edge on opposite side of the commissural attachment zone, (c) eccentric valvular orifice during systole (Fig. 3) [11, 15, 24].

$\mathrm{Chu}$ et al. [11] reported the sensitivity and specificity of transthoracic echocardiography (TTE) were $27 \%$ and $50 \%$ in UAV diagnosis and those of transesophageal echocardiography (TEE) were $75 \%$ and $86 \%$, respectively. The leaflet calcification and poor image quality in some patients (e.g., obese patients, patients with severe chronic obstructive pulmonary disease) are major factors that limit the detection accuracy of TTE $[11,41]$. TEE could circumvent most drawbacks of TTE. Since esophagus is close to the heart and TEE has higher spatial resolution as well as multi-angle visualization of aortic valve, TEE has excellent ultrasonic window and image quality to provide more accurate information of the valve structure for some patients with poor image quality in TTE. These enable TEE to be more accurate than TTE for UAV diagnosis $[11,51]$. But even by TEE, UAV diagnosis is still difficult when a large degree of calcification exists on the leaflet. Compared with BAV and TAV, UAV has the most calcium deposition [34]. Focal or diffuse calcification likely obscures the valve morphology and makes it barely discernible by echocardiography or mimics a calcified raphe so that UAV may be easily misdiagnosed as BAV $[11,35$, 53]. Presumably, UAV should be easier to diagnose in pediatric population due to uncommon encountered aortic valve calcifications and better acoustic windows [43].

There remain other challenges in UAV diagnosis. During diastole, raphes are often misinterpreted as true commissures when the valve is assessed in short-axis plane so that UAV might be misdiagnosed as BAV or TAV $[13,19]$. This is because echocardiography has difficulty in appreciating the height of the zones of apposition [19]. Whereas during systole, the raphes are barely visible and UAV presents its characteristic orifice different from BAV or TAV: the single true commissure opens and an eccentric "teardrop" valvular orifice formed. The visualization of these features is based on the premise that the commissure is properly aligned in the short-axis imaging plane during systole. In fact, misdiagnosis is likely to be unavoidable. Hence, it is required to observe the aortic valve carefully from multiple angles and transducer positions $[12,13,19]$.

Three-dimensional echocardiography (3DE) has potential advantages over two-dimensional echocardiography and has played an incremental role in evaluating valvular anatomic features, presurgical planning, intraprocedural guidance, and post-procedural assessment [54]. $3 \mathrm{DE}$ is a valuable modality for UAV diagnosis. The volumetric imaging technology and matrix-array transducer of $3 \mathrm{DE}$ can offer excellent real time visualization of aortic valve without offline reconstruction, more accurate description of valve morphology and decrease misdiagnosis or missed diagnosis $[11,15,35,54]$. 3DE can observe the aortic valve comprehensively from both aortic and ventricular aspects, define the relationship of the commissures to the coronary ostium, and assess the severity of valvular thickening and calcification accurately $[12,54]$. 3DE is available in both TTE and TEE. 3D TEE has higher spatial resolution than $3 \mathrm{D}$ TTE. Images of $3 \mathrm{D}$ TEE contain unparalleled anatomic details and correspond better with the aortic valve morphology of surgical specimen 
compared to 2D TEE [12, 52, 55]. Occasionally, the spatial resolution and temporal resolution of 3DE are still not enough (e.g., in the setting of heavy valvular calcification).

Echocardiography also can assess the severity of AS and AR and identify the congenital heart disease in UAV patients, the changes of ascending aorta as well as left ventricle in response to the hemodynamic load [36]. Furthermore, dobutamine stress echocardiography may distinguish between true and pseudo severe AS for the AS patients with depressed EF and low-flow/low-gradient [56, 57].

\section{Multi-Modality Imaging}

Although echocardiography is the primary imaging modality for UAV diagnosis in clinical practice, single imaging modality is not perfect. As mentioned above, echocardiography has difficulty in determining the morphology of the aortic valve in patients with poor-quality images and/or with severe aortic valve calcification. Multi-modality imaging might help solve the conundrum, which includes cardiac multi-detector computed tomography (MDCT), cardiac magnetic resonance (CMR), etc. Multi-modality imaging may give full play to the respective advantages of various imaging modalities, improve diagnostic accuracy, and has played an important role in UAV diagnosis.

MDCT is a valuable imaging modality for the diagnosis of UAV. Aortic valve morphology and function can be routinely assessed by MDCT [58]. If excessive calcification make it difficult to differentiate UAV from BAV and TAV in patients with AS, MDCT may prove helpful in distinguishing them [27]. Some reports have shown that MDCT acted as an appropriate approach to detect UAV. For instance, Gibbs et al. [59] reported a case of a young man presenting with intermittent, escalating dyspnea and a harsh systolic murmur at the right upper sternal border on physical examination. TTE showed left ventricular wall thickening and the aortic valve area was $<0.9 \mathrm{~cm}^{2}$. But the morphology of the aortic valve was not clearly seen by TTE due to heavy calcification. Preoperative CT was performed and revealed a UAV, which was in concordance with the surgical findings [59].

Furthermore, MDCT is useful to evaluate aortic valve calcification and quantify it by aortic valve calcification scores. MDCT may contribute to the evaluation of the severity of AS, either indirectly by quantifying valvular calcification or directly through the measurement of valve planimetry $[22,41,60,61]$, and MDCT is widely used to assess the severity and location of the ascending aortic aneurysm/dilatation $[22,61]$.
In addition, it is possible to identify UAV by CMR as well, but in practice, the routine use of CMR is limited due to its insufficient usability and high cost $[22,62,63]$. However, CMR has superiority to assess ventricular volume and function accurately and reproducibly, and provide a quantitative measure of AR [64].

At present, UAVs are discovered mostly by echocardiography, MDCT or CMR rather than operation or autopsy [65]. For some UAV patients (e.g., with heavily calcified aortic valve), multi-modality imaging approach is most effective. Multi-modality imaging that combines various imaging modalities to provide complementary information has obvious advantages over single-modality imaging and is crucial for UAV diagnosis.

\section{Therapeutic Approaches}

The treatment approaches for UAV are significantly different between adults and children. Aortic balloon valvoplasty, surgical valvotomy, commissurotomy, and Ross procedure are main choices in children. Some are palliative procedures and possibly associated with residual or recurrent valve dysfunction and reintervention. The acommissural type usually requires these treatments from neonatal period due to severe AS $[1,40,66]$. In adult population, the most common treatment modality is aortic valve replacement (AVR). Many require AVR in middle age, on average, in their third decade of life [2,67]. In UAV, AVR is about 10-20 years earlier than BAV and 20-30 years earlier than TAV $[5,14,16]$. Some repair techniques such as bicuspidization and tricuspidization of UAV have been reported but long-term data are sparse $[15,25]$. The treatments of associated anomaly of UAV include the replacement of aortic annulus/aortic root/ascending aorta, the repairment of the aortic coarctation, etc.

\section{Conclusion}

UAV is a congenital cardiac anomaly rarely encountered in general population, especially in adult. The unicommissural type is more common in two subtypes. UAV could lead to severe valve dysfunction as well as associated clinical presentation and may be accompanied by other abnormalities $[15,68]$. Echocardiography is the cornerstone of imaging tool to detect UAV. Multi-modality imaging may improve diagnostic accuracy and has played an important role in UAV diagnosis. UAV is easily misdiagnosed as BAV, but there are differences be- 
Table 2. The difference between UAV and BAV

\begin{tabular}{|c|c|c|}
\hline & BAV & UAV \\
\hline Incidence & $0.9-1.36 \%$ in the general population & Lower than BAV \\
\hline Clinical symptoms & Syncope, chest pain, dyspnea, and heart failure & Similar to BAV but develop earlier and progress faster than BAV \\
\hline Commissures, $n$ & 2 & 0 or 1 \\
\hline Cusps, $n$ & 2 & 1 \\
\hline Orifice shape during systole & Elliptical "fish-mouth" orifice & Eccentric "teardrop" orifice, or pinhole-shaped central orifice \\
\hline Leaflet mobility & Slightly reduced & Mild-moderately reduced \\
\hline Aortic dissection & Has higher risk than TAV & Has higher risk than BAV and occurs earlier than BAV \\
\hline Pathologies & Early calcification and degeneration & Similar to BAV but develop earlier and progress faster than BAV \\
\hline Aortic valve dysfunction & AS and/or AR & Similar to BAV but more common, severe, and earlier than BAV \\
\hline
\end{tabular}

tween them in some aspects (Table 2). The therapeutic approaches are different between adults and children. Surgical intervention may be necessary for many UAV patients at a young age [68].

\section{Conflict of Interest Statement}

The author has no conflicts of interest to declare.

\section{Funding Sources}

No funding sources applicable.

\section{Author Contributions}

Jianhong Pan determined the subject of the review and prepared and wrote the manuscript.

\section{References}

1 Edwards JE. Pathologic aspects of cardiac valvular insufficiencies. AMA Arch Surg. 1958 Oct;77(4):634-49.

2 Novaro GM, Mishra M, Griffin BP. Incidence and echocardiographic features of congenital unicuspid aortic valve in an adult population. J Heart Valve Dis. 2003 Nov;12(6):674-8.

3 Roberts WC, Ko JM. Frequency by decades of unicuspid, bicuspid, and tricuspid aortic valves in adults having isolated aortic valve replacement for aortic stenosis, with or without associated aortic regurgitation. Circulation. $2005 \mathrm{Feb} ; 111(7): 920-5$.

4 Singh S, Ghayal P, Mathur A, Mysliwiec M, Lovoulos C, Solanki P, et al. Unicuspid unicommissural aortic valve: an extremely rare congenital anomaly. Tex Heart Inst J. 2015 Jun;42(3):273-6.

5 Kolesar A, Toporcer T, Bajmoczi M, Luczy J, Candik P, Sabol F. Aortic valve repair of a stenotic unicuspid aortic valve in young patients. Ann Thorac Surg. 2018;105(5):1351-6.

6 Cemri M, Cengel A, Timurkaynak T. Pentacuspid aortic valve diagnosed by transoesophageal echocardiography. Heart. 2000 Oct;84(4):E9.

7 Lewin MB, Otto CM. The bicuspid aortic valve: adverse outcomes from infancy to old age. Circulation. 2005 Feb;111(7):832-4.

8 Mookadam F, Thota VR, Garcia-Lopez AM, Emani UR, Alharthi MS, Zamorano J, et al. Unicuspid aortic valve in adults: a systematic review. J Heart Valve Dis. 2010 Jan;19(1):7985.

9 Cripe L, Andelfinger G, Martin LJ, Shooner K, Benson DW. Bicuspid aortic valve is heritable. J Am Coll Cardiol. 2004 Jul;44(1):138-43.

10 Huntington K, Hunter AG, Chan KL. A prospective study to assess the frequency of familial clustering of congenital bicuspid aortic valve. J Am Coll Cardiol. 1997 Dec;30(7): 1809-12.

11 Chu JW, Picard MH, Agnihotri AK, Fitzsimons MG. Diagnosis of congenital unicuspid aortic valve in adult population: the value and limitation of transesophageal echocardiography. Echocardiography. 2010 Oct;27(9):1107-12.

12 Brantley HP, Nekkanti R, Anderson CA, Kypson AP. Three-dimensional echocardiographic features of unicuspid aortic valve stenosis correlate with surgical findings. Echocardiography. 2012 Sep;29(8):E204-7.

13 Tempe DK, Garg M, Tomar AS, Dutta D, Dutta R, Singh AK. Unicuspid aortic valve: transesophageal echocardiographic features. J Cardiothorac Vasc Anesth. 2012 Apr;26(2): 277-9.

14 Moller JH, Nakib A, Eliot RS, Edwards JE. Symptomatic congenital aortic stenosis in the first year of life. J Pediatr. 1966 Nov;69(5): 728-34.

15 Kawase I, Ozaki S, Yamashita H, Uchida S, Nozawa Y, Matsuyama T, et al. Aortic valve reconstruction of unicuspid aortic valve by tri- cuspidization using autologous pericardium. Ann Thorac Surg. 2012 Oct;94(4):1180-4.

16 Falcone MW, Roberts WC, Morrow AG, Perloff JK. Congenital aortic stenosis resulting from a unicommisssural valve. Clinical and anatomic features in twenty-one adult patients. Circulation. 1971 Aug;44(2):272-80.

17 Matsumoto K, Tanaka H, Hiraishi M, Miyoshi T, Tsuji T, Kaneko A, et al. A case of unicommissural unicuspid aortic valve stenosis diagnosed by real time three-dimensional transesophageal echocardiography. Echocardiography. 2011 Sep;28(8):E172-3.

18 Ota T, Okada K, Morimoto Y, Okita Y. Unicuspid aortic valve mimicking quadricuspid valve. Heart Vessels. 2007 Sep;22(5):352-4.

19 Tretter JT, Spicer DE, Mori S, Chikkabyrappa $\mathrm{S}$, Redington AN, Anderson RH. The significance of the interleaflet triangles in determining the morphology of congenitally abnormal aortic valves: implications for noninvasive imaging and surgical management. J Am Soc Echocardiogr. 2016;29(12):1131-43.

20 Sievers HH, Schmidtke C. A classification system for the bicuspid aortic valve from 304 surgical specimens. J Thorac Cardiovasc Surg. 2007 May;133(5):1226-33.

21 Noly PE, Basmadjian L, Bouhout I, Viet Le $\mathrm{VH}$, Poirier N, El-Hamamsy I. New insights into unicuspid aortic valve disease in adults: not just a subtype of bicuspid aortic valves. Can J Cardiol. 2016 Jan;32(1):110-6. 
22 Vahanian A, Alfieri O, Andreotti F, Antunes MJ, Barón-Esquivias $\mathrm{G}$, Baumgartner $\mathrm{H}$, et al. Guidelines on the management of valvular heart disease (version 2012): the Joint Task Force on the management of valvular heart disease of the European Society of Cardiology (ESC) and the European Association for Cardio-Thoracic Surgery (EACTS). Eur J Cardiothorac Surg. 2012 Oct;42(4):S1-44.

23 Franciulli M, Aicher D, Rädle-Hurst T, Takahashi H, Rodionycheva S, Schäfers HJ. Root remodeling and aortic valve repair for unicuspid aortic valve. Ann Thorac Surg. 2014 Sep; 98(3):823-9.

24 Ewen S, Karliova I, Weber P, Schirmer SH, Abdul-Khaliq H, Schöpe J, et al. Echocardiographic criteria to detect unicuspid aortic valve morphology. Eur Heart J Cardiovasc Imaging. 2019;20(1):40-4.

25 Schäfers $\mathrm{HJ}$, Aicher D, Riodionycheva S, Lindinger A, Rädle-Hurst T, Langer F, et al. Bicuspidization of the unicuspid aortic valve: a new reconstructive approach. Ann Thorac Surg. 2008 Jun;85(6):2012-8.

26 Aicher D, Bewarder M, Kindermann M, Abdul-Khalique $H$, Schäfers $H J$. Aortic valve function after bicuspidization of the unicuspid aortic valve. Ann Thorac Surg. 2013 May; 95(5):1545-50.

27 Saito Y, Takaoka H, Funabashi N, Ozawa K, Tamura Y, Saito M, et al. A case of very severe aortic stenosis due to unicuspid aortic valve mimicking bicuspid aortic valve with calcification on cardiac computed tomography. Int J Cardiol. 2016 Jul;215:516-8.

28 Vahanian A, Alfieri O, Al-Attar N, Antunes M, Bax J, Cormier B, et al. Transcatheter valve implantation for patients with aortic stenosis: a position statement from the European Association of Cardio-Thoracic Surgery (EACTS) and the European Society of Cardiology (ESC), in collaboration with the European Association of Percutaneous Cardiovascular Interventions (EAPCI). Eur Heart J. 2008 Jun;29(11):1463-70.

29 O'Sullivan CJ, Windecker S. Implications of bicuspid aortic valves for transcatheter aortic valve implantation. Circ Cardiovasc Interv. 2013 Jun;6(3):204-6.

30 Kwon HJ, Park JH, Kim SS, Sun BJ, Jin SA, $\mathrm{Kim} \mathrm{JH}$, et al. Severe aortic stenosis associated with unicommissural unicuspid aortic valve in a middle aged male. J Cardiovasc Ultrasound. 2016 Sep;24(3):247-50.

31 Sniecinski RM, Shanewise JS, Glas KE. Transesophageal echocardiography of a unicuspid aortic valve. Anesth Analg. 2009 Mar; 108(3): 788-9.

32 Krepp JM, Roman MJ, Devereux RB, Bruce A, Prakash SK, Morris SA, et al. Bicuspid and unicuspid aortic valves: different phenotypes of the same disease? Insight from the GenTAC Registry. Congenit Heart Dis. 2017 Dec; 12(6):740-5.
33 Roberts WC, Ko JM. Relation of weights of operatively excised stenotic aortic valves to preoperative transvalvular peak systolic pressure gradients and to calculated aortic valve areas. J Am Coll Cardiol. 2004 Nov;44(9): 1847-55.

34 Roberts WC, Ko JM. Weights of operativelyexcised stenotic unicuspid, bicuspid, and tricuspid aortic valves and their relation to age, sex, body mass index, and presence or absence of concomitant coronary artery bypass grafting. Am J Cardiol. 2003 Nov;92(9):1057-65.

35 Chester R, Sahni S, Huynh T. A case of late presenting unicuspid aortic valve in a 62-yearold female. Echocardiography. 2015 Jul;32(7): 1203-5.

36 Thota V, Mookadam F. Unicuspid aortic valve. In: Chen YF, editor. Aortic valve. InTech, Open Access; 2011. p. 269-74.

37 Nanda S, Longo S, Arastu MI. Unicuspid aortic valve, hand anomalies: a heart-hand syndrome. Am J Med Sci. 2010 Mar;339(3):2969.

38 Montealegre-Gallegos M, Shakil O, Jiang L, Mahmood F. Unicommissural unicuspid aortic valve. Ann Card Anaesth. 2014 Jan-Mar; 17(1):40-1.

39 Fijalkowski M, Jaguszewski M, Pienkowska J, Fijalkowska J, Rogowski J, Rynkiewicz A. Incidental diagnosis of unicuspid aortic valve in an asymptomatic adult. Kardiol Pol. 2013; 71(2):209.

40 Yamanaka T, Fukatsu T, Ichinohe Y, Komatsu $\mathrm{H}$, Seki M, Sasaki K, et al. An adult case of unicommissural unicuspid aortic valve diagnosed based on the intraoperative findings. Intern Med. 2016;55(18):2643-8.

41 Cueff C, Serfaty JM, Cimadevilla C, Laissy JP, Himbert D, Tubach F, et al. Measurement of aortic valve calcification using multislice computed tomography: correlation with haemodynamic severity of aortic stenosis and clinical implication for patients with low ejection fraction. Heart. 2011 May;97(9):721-6.

42 Tokue M, Hara H, Sahara N, Yamazaki K, Yamashita $\mathrm{H}$, Takahashi K, et al. A case of severe unicuspid aortic valve stenosis: valve repair with tricuspidization in an adult. World J Pediatr Congenit Heart Surg. 2015 Oct;6(4): 658-62.

43 Mookadam F, Thota VR, Lopez AM, Emani UR, Tajik AJ. Unicuspid aortic valve in children: a systematic review spanning four decades. J Heart Valve Dis. 2010 Nov; 19(6):67883.

44 Nishimura RA, Otto CM, Bonow RO, Carabello BA, Erwin JP, Guyton RA, et al. 2014 AHA/ACC guideline for the management of patients with valvular heart disease: a report of the American College of Cardiology/ American Heart Association Task Force on practice guidelines. Circulation. 2014 Jun; 129(23):2440-92.

45 Nabati M, Vahedi L, Hakkakian V, Ghaemian A, Bagheri B. Unicuspid aortic valve in a middle-aged man: a rare case report. J Echocardiogr. 2014 Jun;12(2):65-7.
46 Tadros TM, Klein MD, Shapira OM. Ascending aortic dilatation associated with bicuspid aortic valve: pathophysiology, molecular biology, and clinical implications. Circulation. 2009 Feb;119(6):880-90.

47 Agnihotri AK, Desai SC, Lai YQ, Fitzsimons MG, Hilgenberg AD, Vlahakes GJ. Two distinct clinical presentations in adult unicuspid aortic valve. J Thorac Cardiovasc Surg. 2006 May;131(5):1169-70.

48 Roberts CS, Roberts WC. Dissection of the aorta associated with congenital malformation of the aortic valve. J Am Coll Cardiol. 1991 Mar;17(3):712-6.

49 Larson EW, Edwards WD. Risk factors for aortic dissection: a necropsy study of 161 cases. Am J Cardiol. 1984 Mar;53(6):849-55.

50 Ishigami H, Iwase M, Hyoudo K, Aoyama I, Ito $\mathrm{M}$, Tajima $\mathrm{K}$, et al. A case of unicuspid aortic valve associated with a single coronary artery and ventricular septal defect. J Med U1trason. 2005 Jun;32(2):65-70.

51 Hahn RT, Abraham T, Adams MS, Bruce CJ, Glas KE, Lang RM, et al. Guidelines for performing a comprehensive transesophageal echocardiographic examination: recommendations from the American Society of Echocardiography and the Society of Cardiovascular Anesthesiologists. Anesth Analg. 2014 Jan; 118(1):21-68.

52 Nakao T, Watanabe H, Takeda N, Takanashi $S$, Nagai R. The efficacy of real-time three-dimensional transoesophageal echocardiography in detecting unicuspid aortic valve. Eur Heart J Cardiovasc Imaging. 2012 Nov; 13(11):966.

53 Essandoh M, Castellon-Larios K, ZuletaAlarcon A, Portillo JG, Crestanello JA. Unicuspid aortic stenosis in a patient with Turner syndrome: a case report. Front Cardiovasc Med. 2014;1:14.

54 Lang RM, Tsang W, Weinert L, Mor-Avi V, Chandra S. Valvular heart disease. The value of 3-dimensional echocardiography. J Am Coll Cardiol. 2011 Nov;58(19):1933-44.

55 Dod HS, Nanda NC, Agrawal GG, Ravi BS, Htay T, Upendram SK. Three-dimensional transesophageal echocardiographic assessment of aortic valve pathology. Am J Geriatr Cardiol. 2003 May-Jun;12(3):209-13.

56 Monin JL, Monchi M, Gest V, Duval-Moulin AM, Dubois-Rande JL, Gueret P. Aortic stenosis with severe left ventricular dysfunction and low transvalvular pressure gradients: risk stratification by low-dose dobutamine echocardiography. J Am Coll Cardiol. 2001 Jun; 37(8):2101-7.

57 Blais C, Burwash IG, Mundigler G, Dumesnil JG, Loho N, Rader F, et al. Projected valve area at normal flow rate improves the assessment of stenosis severity in patients with low-flow, low-gradient aortic stenosis: the multicenter TOPAS (Truly or Pseudo-Severe Aortic Stenosis) study. Circulation. 2006 Feb;113(5): 711-21. 
58 Szymczyk K, Polguj M, Szymczyk E, Bakoń L, Pacho R, Stefańczyk L. Assessment of aortic valve in regard to its anatomical variants morphology in 2053 patients using 64-slice CT retrospective coronary angiography. BMC Cardiovasc Disord. 2016 May; 16:89.

59 Gibbs WN, Hamman BL, Roberts WC, Schussler JM. Diagnosis of congenital unicuspid aortic valve by 64 -slice cardiac computed tomography. Proc (Bayl Univ Med Cent). 2008 Apr;21(2):139.

60 Capoulade R, Pibarot P. Assessment of aortic valve disease: role of imaging modalities. Curr Treat Options Cardiovasc Med. 2015 Nov; 17(11):49.

61 Baumgartner H, Falk V, Bax JJ, De Bonis M, Hamm C, Holm PJ, et al. 2017 ESC/EACTS guidelines for the management of valvular heart disease. Eur Heart J. 2017;38(36):2739_ 91.

62 Debl K, Djavidani B, Buchner S, Poschenrieder F, Heinicke N, Schmid C, et al. Unicuspid aortic valve disease: a magnetic resonance imaging study. Rofo. 2008 Nov;180(11):983-7.

63 Dursun M, Yilmaz S, Sayin OA, Ugurlucan M, Ucar A, Yekeler E, et al. Combination of unicuspid aortic valve, aortic coarctation, and aberrant right subclavian artery in a child: $\mathrm{MR}$ imaging and CTA findings. Cardiovasc Intervent Radiol. 2007 May-Jun;30(3):547-9.

64 Cawley PJ, Maki JH, Otto CM. Cardiovascular magnetic resonance imaging for valvular heart disease: technique and validation. Circulation. 2009 Jan;119(3):468-78.
65 Roberts WC, Vowels TJ, Ko JM. Natural history of adults with congenitally malformed aortic valves (unicuspid or bicuspid). Medicine. 2012 Nov;91(6):287-308

66 Miyamoto T, Sinzobahamvya N, Wetter J, Kallenberg R, Brecher AM, Asfour B, et al. Twenty years experience of surgical aortic valvotomy for critical aortic stenosis in early infancy. Eur $J$ Cardiothorac Surg. 2006 Jul;30(1):35-40.

67 Higashi H, Ogimoto A, Inoue K, Tokunaga N, Iio C, Aono J, et al. Eccentric left ventricular hypertrophy in aortic stenosis caused by unicuspid aortic valve. Circ J. 2017;81(6):895-7.

68 Dostálová G, Hlubocká Z, HlubockýJ, Paleček $\mathrm{T}$, Linhart A. Severe aortic regurgitation caused by unicuspid aortic valve. Kardiol Pol. 2018;76(2):478. 